\title{
A case report of Amyand hernia-radiological diagnosis and literature review
}

\author{
Mohamed rafi Kathar hussain ${ }^{1 *}$ (D) and Kulasekeran $\mathrm{N}^{2}$
}

\begin{abstract}
Background: The hernia is defined as the protrusion of any organ or a part of it through the wall or fascia or any connective tissue which normally encloses that organ. Among the hernias, an inguinal hernia is the most common type. In the inguinal hernia, Amyand hernia is one of the rare types, in which the appendix will herniate through the inguinal canal. The incidence of Amyand hernia is less than 1\% (Namdev et al., Int Surg J 7:2072, 2020).
\end{abstract}

Case presentation: We are reporting a case of Amyand hernia, which was diagnosed incidentally in the patient who had been referred to computerized tomography (CT) for a malignant melanoma metastasis screening. Our case is unique in that pre-operative diagnosis of the Amyand hernia is rarely reported in the literature. We can diagnose the type 1 Amyand hernia with utmost confidence.

Conclusion: Pre-operative diagnosis of type 1 Amyand hernia can be made with utmost certainty by CT.

Keywords: Amyand, Computerized tomography, Appendix, Inguinal, Ultrasonogram, Surgery, Imaging

\section{Background}

The hernia is defined as the protrusion of any organ or a part of it through the wall or fascia or any connective tissue which normally encloses that organ. Hernias can occur due to various factors. The most common etiology is due to the weakness of the muscular layer or any persistent congenital or acquired defect in the wall. It can be reducible, in which the sac contents go back from the sac into the cavity. Or it can be irreducible or incarcerated hernia when the sac content does not go back. The most common cause of irreducibility is due to the development of adhesion. An incarcerated hernial loop can go for strangulation at any time, in which blood supply to the loop is lost leading to the development of gangrene.

Among the hernia, an inguinal hernia is the most common type. In the inguinal hernia, Amyand hernia is one of the rare types with an incidence of less than $1 \%$

\footnotetext{
* Correspondence: radiologistrafi1984@gmail.com

${ }^{1}$ Assistant Professor, Department of Radio-diagnosis, Sri Manakula Vinaygar

Medical College, Kalitheerthalkuppam, Puducherry, India

Full list of author information is available at the end of the article
}

[1]. Amyand hernia is defined as the presence of an appendix within the hernial sac, with or without appendicitis.

Surgical management changes, when the surgeon finds the presence of an inflamed appendix within the hernial sac. Therefore, both surgeons and radiologists are concerned about the contents of the hernia sac. Preoperative diagnosis of Amyand hernia can be made with $\mathrm{CT}$, through which imaging will play an important role in surgical management.

\section{Case presentation}

A 75-year-old male patient, who was a known case of malignant melanoma of the right foot, had come with the complaints of recent onset of right groin swelling. He had no other presenting complaints. His vital parameters were stable. Examinations of the respiratory, cardiovascular system, and central nervous system are within normal limits. The abdomen was soft with no organomegaly. Local examination of the right femoral region showed right femoral lymphadenopathy. Clinical diagnosis of right femoral lymph nodal metastasis was

\section{Springer Open}

(c) The Author(s). 2020 Open Access This article is licensed under a Creative Commons Attribution 4.0 International License, which permits use, sharing, adaptation, distribution and reproduction in any medium or format, as long as you give appropriate credit to the original author(s) and the source, provide a link to the Creative Commons licence, and indicate if changes were made. The images or other third party material in this article are included in the article's Creative Commons licence, unless indicated otherwise in a credit line to the material. If material is not included in the article's Creative Commons licence and your intended use is not permitted by statutory regulation or exceeds the permitted use, you will need to obtain permission directly from the copyright holder. To view a copy of this licence, visit http://creativecommons.org/licenses/by/4.0/. 
made. Following that, the CECT examination of the thorax and abdomen was requested to look for any other metastasis. No previous imaging was available.

Triple phase CT examination of the chest and abdomen was performed in Philips 16 slice MX CT. It shows significantly enlarged right femoral lymph nodes with areas of central necrosis (Fig. 1a and b). The liver shows multiple metastases. Incidentally, the patient had a right inguinal hernia. Terminal ileum, ileocecal junction, and cecum are within the hernial sac (Fig. 2). Normal appendix with the presence of intraluminal air and normal peri-appendiceal fat is noted within the inguinal hernia, which is seen extending up to the base of the scrotum (Fig. 3). No signs of appendicitis. Small and large bowel loops are collapsed with no signs of bowel loop obstruction.

Final radiological diagnosis of right necrotic femoral metastatic lymphadenopathy, liver metastasis, and type 1 Amyand hernia was made. The patient was referred to the surgical team for further management. Unfortunately, the patient had lost follow-up after that.

Imaging can diagnose type 1 Amyand hernia with utmost confidence before surgery. Most of the cases in the literature are diagnosed on the surgical bed.

\section{Discussion}

There are many types of hernias, of which inguinal hernia is the most common type. The contents of the hernial sac vary from case to case [1]. In most cases, inguinal hernia contains omentum with small bowel loops [2]. The presence of appendix or otherwise known as a vermiform appendix within the inguinal hernial sac is rare [3]. Further presence of inflamed appendix within the hernia sac is very rare with an incidence of $0.1 \%$ [4]. The propensity to develop appendicitis is due to the compression of the appendix at the level of neck of the sac or due to impaired vascular supply leading to infection [4].

The presence of the appendix within the femoral hernia was first reported by De Garengeot in 1731 [4]. The first reported appendicectomy in the right inguinal hernia was performed by Claudius Amyand in 1736 [4] which was done in St. George Hospital, on an 11-year-old boy [5]. After that, the presence of appendix within the hernial sac whether it is inflamed or not was called "Amyand Hernia". Although inguinal hernia is commonly encountered lower abdominal surgical pathology, which is the everyday routine bread and butter of general surgeons, sometimes it can pose an intra-operative dilemma [4].

There are many different types of unusual hernia. To name a few, the presence of Meckel diverticulum within the hernial sac is called Littre's hernia, the presence of the portion of the bowel wall within the hernial sac is called Richter hernia, and presence of appendix within the femoral canal is called De Garengeot hernia [4].

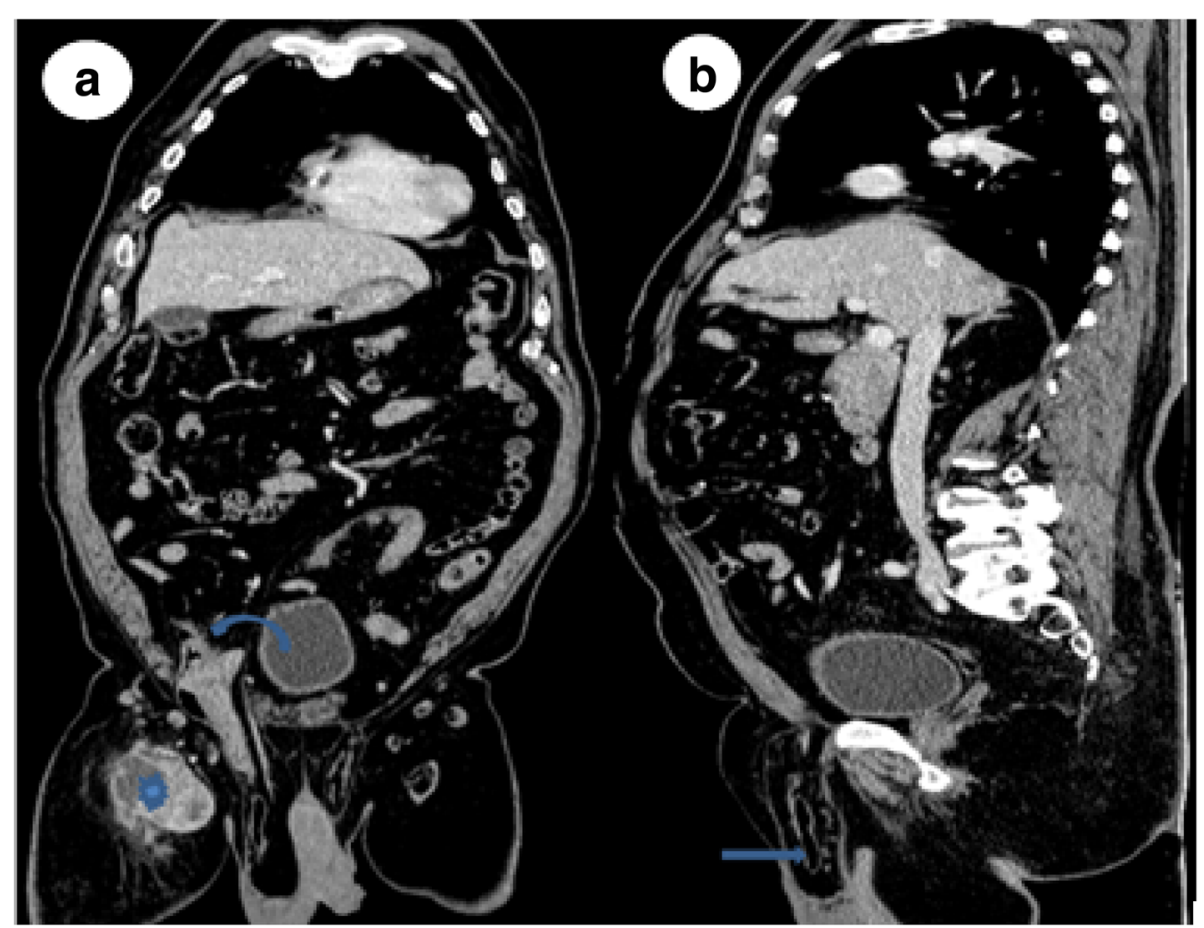

Fig. 1 a, b CT abdomen coronal and sagittal sections venous phase shows terminal ileum, cecum, and normal appendix inside the right inguinal canal. Also noted is right femoral necrotic lymph nodal metastasis from the malignant melanoma (straight arrow indicates appendix in the right scrotal region, curved arrow indicate ileocecal junction, star indicates necrotic lymph nodal metastasis) 


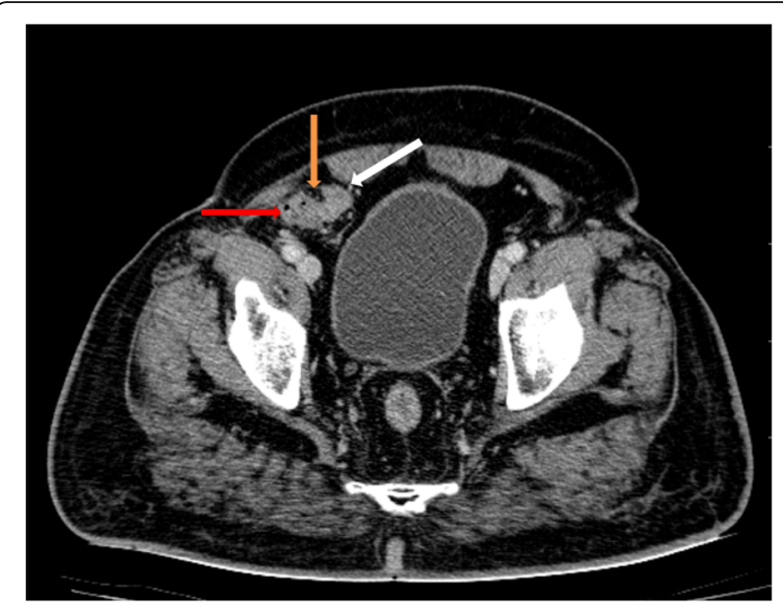

Fig. 2 CT abdomen axial section venous phase at the level of the pelvis shows presence of cecum (red arrow), ileocecal junction (yellow arrow), and terminal ileum (white arrow) are within the hernial sac

Amyand hernia is usually found on the right side and more common in males [6]. The most common presentation is an indirect inguino-scrotal hernia [6]. The right side location is attributed to the presence of the appendix on the right side [1]. Left side Amyand hernia has also been reported, due to gut malrotation, situs inversus totalis, and very mobile cecum [1]. Few cases of Amyand hernia also had been reported in females [6, 7]. The age at presentation ranges from 3 weeks to 92 years [3]. Amyand hernia is three times more likely to be seen in the pediatric population, due to the presence of patent processes vaginalis [8].

Amyand hernia is classified into four types based upon the presence of appendicular inflammation, associated peritonitis, or any other abdominal pathology by Losanoff and Basson [9, 10]. Surgical management depends upon the types of Amyand hernia [10] (Table 1).

Sometimes appendix can herniate through the defect in the previous incisional site. Appendix is the content of the sac in the post-operative incisional hernia. It is added as a new fifth type in the Losanoff and Basson classification of Amyand hernia [7]. This is further classified into three subtypes, namely VA, VB, and VC based upon the presence of appendicular inflammation or any other associated intraabdominal pathology.

Imaging plays an important role in diagnosing Amyand hernia. The ultrasound features of Amyand hernia are the presence of a non-compressible, dilated, blind-ending bowel loop with a luminal diameter of more than $7.2 \mathrm{~mm}$, within the inguinal canal with or without surrounding inflammation [11]. In CT, signs of Amyand hernia are the presence of an appendix within the inguinal canal with or without inflammation. Signs of the inflamed appendix are increased luminal diameter
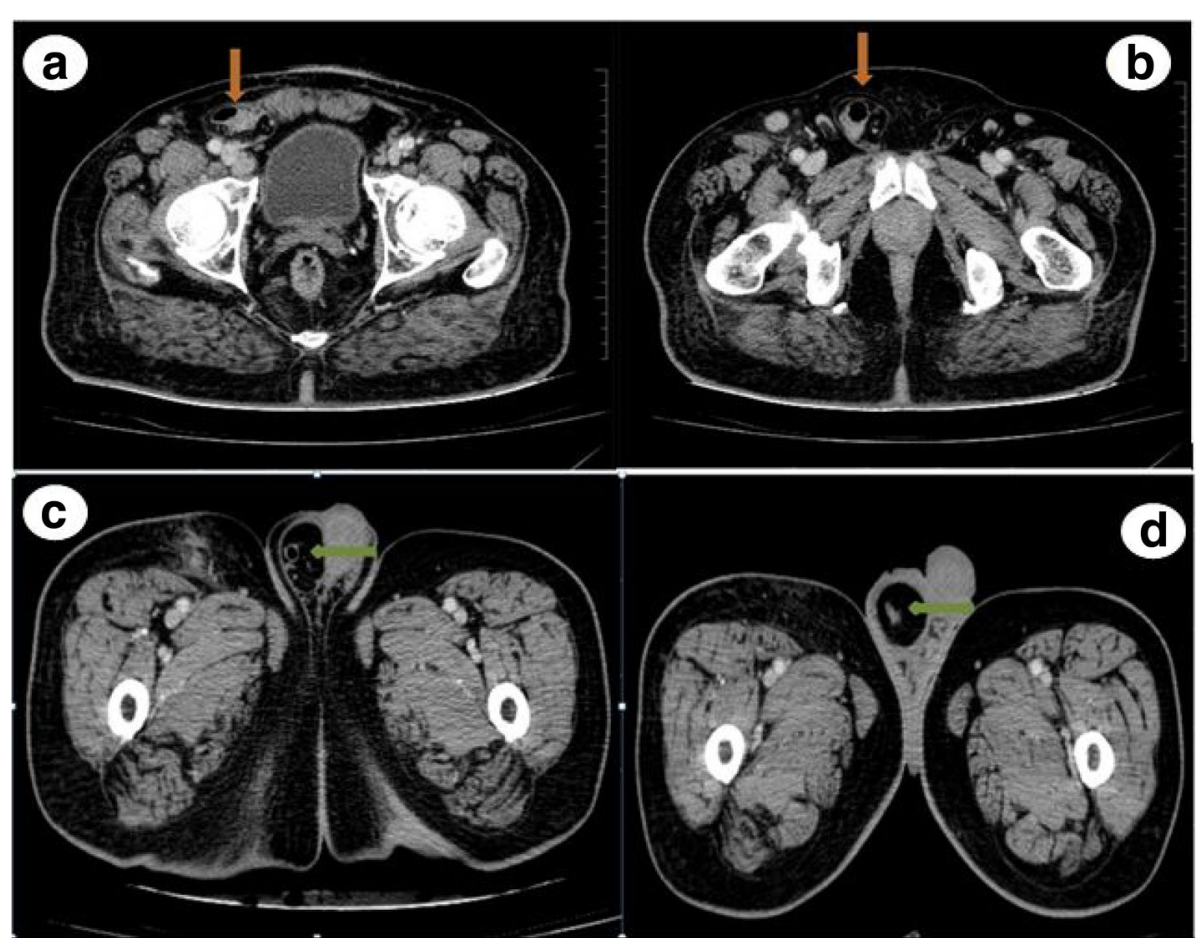

Fig. $3 \mathrm{CT}$ abdomen axial section venous phase $(\mathbf{a}, \mathbf{b})$ at the level of the pelvis shows cecal tip (arrow mark) seen within the right inguinal canal. Few section below that $(\mathbf{c}, \mathbf{d})$ shows the presence of normal appendix (arrow mark) with intraluminal air and normal peri-appendiceal fat (arrow mark) 
Table 1 Losanoff and Basson classification of Amyand's hernia with their surgical management

\begin{tabular}{lll}
\hline Classification & Description & Surgical management \\
\hline Type 1 & Normal appendix in an inguinal hernia & Hernia reduction, mesh repair \\
Type 2 & Acute appendicitis in an inguinal hernia, without abdominal sepsis & Appendectomy, primary repair of hernia without mesh \\
Type 3 & $\begin{array}{l}\text { Acute appendicitis in an inguinal hernia, with abdominal wall or } \\
\text { peritoneal sepsis }\end{array}$ & Laparotomy, appendectomy, primary repair without mesh \\
Type 4 & Acute appendicitis in an inguinal hernia, with abdominal pathology & Manage as type 1-3, investigate pathology as needed \\
\hline
\end{tabular}

with associated peri-appendicular fat stranding and fluid collection, associated cecal thickening, and presence of appendicolith in few cases.

The pre-operative diagnosis of Amyand hernia had been reported in certain literature $[5,12]$. But most of the time, it was diagnosed intraoperatively $[1,2,7]$. The reason for that is the pre-operative imaging investigation not routinely requested by surgeons [3]. So there are statements in the literature that pre-operative CT "can" be helpful [1] or "practically impossible" [4] or minimal functionality [7]. But pre-operative CT will give valuable information regarding the contents of the hernia sac.

The limitation of this case report is that we had lost the follow-up of the patient after surgical referral, so surgical diagnosis is not available.

\section{Conclusion}

In contrary to the statement of many literatures, imaging can easily diagnose Amyand hernia. We want to emphasize the fact that pre-operative CT will give valuable information regarding the contents of the hernia sac, which helps in surgical management of the patient and prevents the unexpected surprise on the surgical bed.

\section{Abbreviations}

CT: Computerized tomography; CECT: Contrast-enhanced computerized tomography

\section{Acknowledgements}

We thank my colleagues Dr. Anand and Dr. Elamparidhi for their useful suggestion.

\section{Authors' contributions \\ Dr. MRKH (1) had made substantial contributions to concept, design, acquisition, interpretation of data, and drafting the article. Dr. NK (2) had made substantial contributions to intellectual content and gave final approval of the version to be submitted. The authors have read and approved the transcript.}

\section{Funding}

$\mathrm{Nil}$

\section{Availability of data and materials}

Available

\section{Ethics approval and consent to participate}

Ethical approval not needed and since it is a retrospective case report study. Written consent had been obtained from the participant for participation.

\section{Competing interests}

$\mathrm{Nil}$

\section{Author details}

${ }^{1}$ Assistant Professor, Department of Radio-diagnosis, Sri Manakula Vinaygar Medical College, Kalitheerthalkuppam, Puducherry, India. ${ }^{2}$ Professor and HOD, Department of Radio-diagnosis, Sri Manakula Vinaygar Medical College, Kalitheerthalkuppam, Puducherry, India.

Received: 3 August 2020 Accepted: 27 October 2020

Published online: 10 November 2020

\section{References}

1. Namdev G, Sanjay P, Varun S, Padnanabh D (2020) Amyand's hernia: a case report. Int Surg J 7:2072. https://doi.org/10.18203/2349-2902.isj20202440

2. Morales-Cárdenas A, Ploneda-Valencia CF, Sainz-Escárrega VH et al (2015) Amyand hernia: case report and review of the literature. Ann Med Surg (Lond) 4(2):113-115Published 2015 Apr 14. https://doi.org/10.1016/j.amsu. 2015.03.007

3. Ikram S, Kaleem A, Ahmad SM (2018) Amyand hernia: a literature review of the diagnosis and management of the rare presentation of the wandering appendix. J Rare Disord Diagn Ther 4:1. https://doi.org/10.21767/2380-7245. 100171

4. Mhatre H, Kanake V, Nandu V (2016) Amyand's hernia: a rare case presentation. Int Surg J [S.I.], v. 2(4):737-740 ISSN 2349-2902

5. Al Maksoud A, Ahmed A (2015) Left Amyand's hernia: an unexpected finding during inguinal hernia surgery. Int I Surg Case Rep 14:7-9

6. Gurer A, Ozdogan M, Ozlem N, Yildirim A, Kulacoglu H, Aydin R (2006) Uncommon content in groin hernia sac. Hernia. 10(2):152-155. https://doi. org/10.1007/s10029-005-0036-4

7. Bhatti SI, Hashmi MU, Tariq U, Bhatti HI, Parkash J, Fatima Z (2018) Amyand's hernia: a rare surgical pathology of the appendix. Cureus 10(6): e2827Published 2018 Jun 18. https://doi.org/10.7759/cureus.2827

8. Luciana L et al (2019) Pediatric amyand hernia: case report in Sanjiwani Gianyar hospital Bali-Indonesia. Intisari Sains Medis 10:n. pag

9. Losanoff JE, Basson MD (2008) Amyand hernia: a classification to improve management. Hernia. 12(3):325-326. https://doi.org/10.1007/s10029-0080331-y

10. Green J, Gutwein LG (2013) Amyand's hernia: a rare inguinal hernia. J Surg Case Rep 2013(9):rij043Published 2013 Sep 11. https://doi.org/10.1093/jscr/ rit043

11. Ornelas-Cortinas G, Cantu-Gonzalez J, Enríquez-Rodriguez R, MontemayorMartinez A, Negreros-Osuna A, Cortinas-Gonzalez J et al (2019) Acute appendicitis in Amyand's hernia: ultrasound findings and histopathology correlation. A case report. J Surg Case Rep 2019(11):riz335

12. Chiong C, Yoon P, Boseto F (2019) Appendicitis within an Amyand's hernia: a surprising finding. J Surg Case Rep 2019(3):riz055Published 2019 Mar 12. https://doi.org/10.1093/jscr/rjz055

\section{Publisher's Note}

Springer Nature remains neutral with regard to jurisdictional claims in published maps and institutional affiliations.

\section{Consent for publication}

Written consent had been obtained. 